\title{
Optimized Thermal Efficiency of Rotor and Stator Using CFD
}

\author{
Md. Shahwaz Hussain \\ M. Tech. Scholar \\ All Saints College of Technology Bhopal, MP \\ India \\ shahwaz0116@gmail.com
}

\author{
Sujata Pouranik \\ Assistant Professor \\ All Saints College of Technology Bhopal, MP \\ India \\ sujatapouranik@gmail.com
}

\begin{abstract}
The space between rotor and stator plays a very important role in the design and performance of rotating machinery. The thickness of the gap can vary considerably depending on the size and operating conditions for the different types of rotating machines. Analysis the air velocity and temperature distribution over the air flow gap in stator and motor. Changing the design of rotor to develop turbulence in air flow gap. Compare the velocity and temperature distribution of proposed design with previous studies. The simulation results pinpoint also the periodic heat transfer pattern from the rotor surface and this provides useful information for the prediction of the temperature distribution inside the rotating electrical machine. The simulation results of case- 1 show about $117^{\circ} \mathrm{C}$ temperature inside the rotor machine. Then increase the number of slot inside the rotor machine the total temperature of the rotor machine decreases up to $76^{\circ} \mathrm{C}$. Due to low temperature total efficiency of the system increases. And also reduces the loss due to heat. The turbulence effect inside the rotor increase in third case. Due to turbulence effect the air cover large amount of area inside the rotor. So total temperature of the rotor casing decreases. In a system where volume is held constant, there is a direct relationship between Pressure and Temperature. For this case, when the pressure increases then the temperature also increases. When the pressure decreases, then the temperature decreases. So pressure in third case decrease upto1.26Pa and temperature $76^{\circ} \mathrm{C}$.
\end{abstract}

Keywords: Rotor, Temperature, CFD, ANSYS.

\section{INTRODUCTION}

The space between rotor and stator plays a very important role in the design and performance of rotating machinery. The thickness of the gap can vary considerably depending on the size and operating conditions for the different types of rotating machines. For example, with smaller engines, a very small air gap, often less than a millimeter, is maintained to reduce electromagnetic losses and increase efficiency. On the other hand, with larger rotating machines, a very high magnetic field is generated, which can drive the rotor towards the stator with a very high force. Therefore, a wider space is often maintained to avoid contact between the rotor and the stator during engine operation. The machine design process also requires knowledge of the temperature distribution and maximum internal temperature for a given operating condition. The performance and life expectancy of the machine depend on maintaining the temperature during the operation of the machine, in accordance with the instructions and design specifications. Furthermore, the maximum output power is also limited by the increase in temperature in electrical machines [1].

\section{LITERATURE REVIEW}

Berker Bilgin et al. [1] this review provides a comprehensive overview of the latest analytical models and methods for multidisciplinary design of electric motors for various applications, including power and drive systems for electrified vehicles and thrusters. The article aims to provide designers with examples of electric motors and results on the use of various analysis techniques on electric motors.

$\mathrm{K}$. Wang et al. [2] in this article, the Modular Consequent Pole (MCP) rotor is integrated into the Internal Permanent Magnet (IPM) machine with a broken slot to take advantage of the powerful flow focusing effect and reduce leakage flow. Therefore, it is possible to improve the torque density and the utilization ratio of the PM material.

Sara Sadr et al. [3] this article presents the use of CFD (Computational Fluid Dynamics) simulations to study air 
flows in very tight air spaces in high speed electric cars. For this purpose, the shear stress of the wall on the surface of the rotor, the coefficient of friction of the rotor skin and the losses due to the aging of the wind are numerically evaluated. CFD results are used to closely analyze air flows and we propose a method based on these numerical results that can be used to determine the classic friction coefficient of the rotor skin. The results are compared with the classic correlations.

Jungmayr, G. et al. [4] this article presents magnetic gear motors compared to synchronous permanent magnet machines, which offer higher torque densities. Up to now, the topologies of permanent magnet machines with magnetic teeth examined have been almost exclusively constructions in which the motor and the magnetic gear are arranged coaxially on the same plane. This article presents a new magnetic drive machine, in which the motor and the coaxial magnetic gear are arranged side by side. The concept, the design process, the prototype and the first measurements are presented.

\section{OBJECTIVE}

- Analysis the air velocity and temperature distribution over the air flow gap in stator and motor.

- Changing the design of rotor to develop turbulence in air flow gap.

- Compare the velocity and temperature distribution of proposed design with previous studies.

\section{Methodology}

A. Thermal Analysis of Rotating Machines using CFD.

Preparation of model: A CAD model is prepared in CATIA

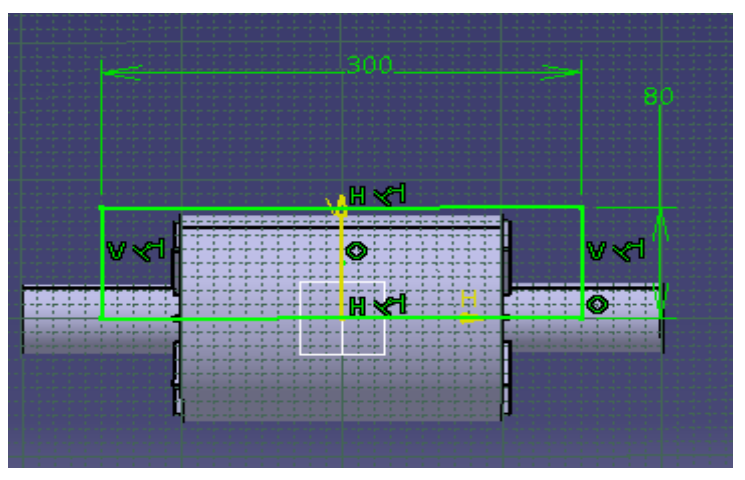

Fig. 1 Catia model design of Rotating Machines

\section{B. Steps of Working}

Step 1: Collecting information and data related to Rotating Machines.
Step 2: A fully parametric model of the Rotating Machines for 2 cases.

Step 3: Model obtained in Step 2 is analyzed using ANSYS 18.2.

Step 4: Finally, we compare the results obtained from ANSYS

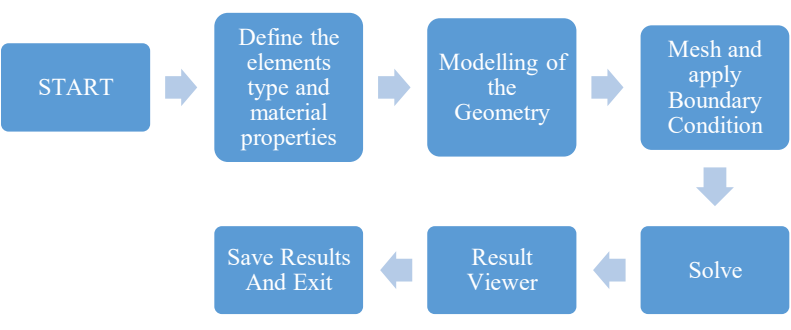

Fig. 2 Setup of working

\section{Finite elements analysis}

Finite elements analysis is a branch of fluid mechanics that uses numerical analysis and data structures to solve and analyze problems that involve solid structure. For the present work ANSYS 18.2 software used.

\section{ANSYS Capabilities:}

In finite element analysis ANSYS software is used that helps engineers for performing the following tasks:

- To build computer prototype, components, transfer CAD models of structures in a system products.

- Enhances the profile of structural member with shape optimization.

- Physical responses, such as stress levels, temperature distributions, or electromagnetic field scan be studied.

- To reduce production costs optimization of design is done early in the development process.

- Testing of prototypes is done in environments where it otherwise would be undesirable or impossible (for example, biomedical applications).

Graphical user interface (GUI) in ANSYS gives users an easy, interactive approach to documentation, program functions, commands, and reference material. To navigate through the ANSYS program an intuitive menu system is used by users. Input data can be given using a mouse, a keyboard, or a combination of both. 


\section{E. Steps Of ANSYS Analysis}

The different analysis steps involved in ANSYS are mentioned below.

\section{1. preprocessor}

The model setup is basically done in preprocessor. The different steps in pre-processing are

- $\quad$ Build the model

- Define materials

- Generation of element mesh

2. Building The Model

- Creating a solid model within Catia

- First creating air domain according to base paper. The rotor out casing size is $300 \mathrm{~mm}$ length and radius and 160 diameter in length.

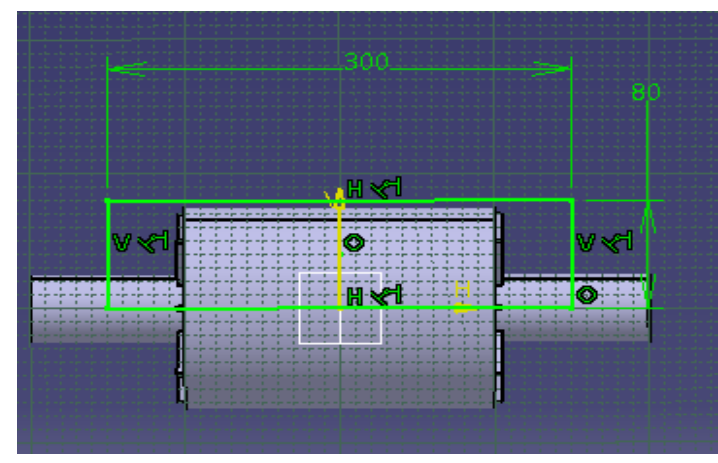

Fig. 3. CAD model prepared in Catia (base paper model)

- Design rotor with 8 slot

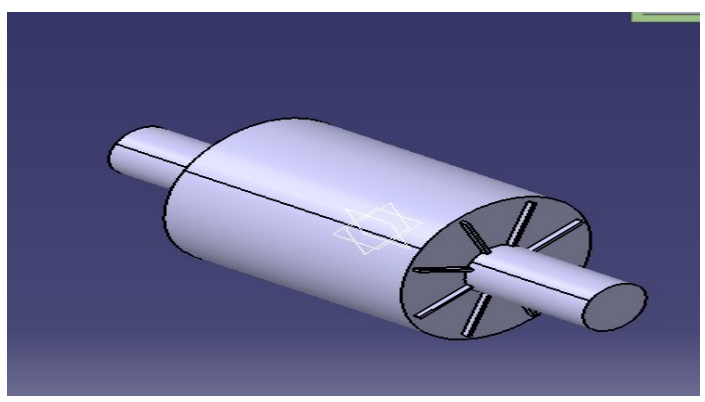

Fig. 4. CAD model prepared in Catia (base paper model)

3. Import Model in ANSYS

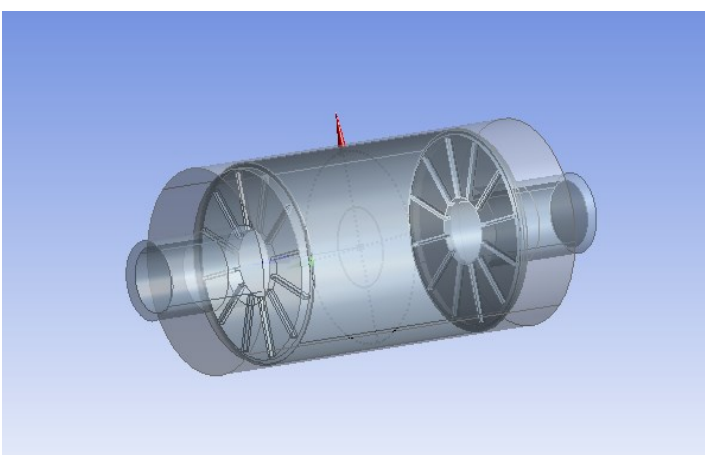

Fig. 5. Import model in ANSYS

F. Case-1:-Rotor Machine

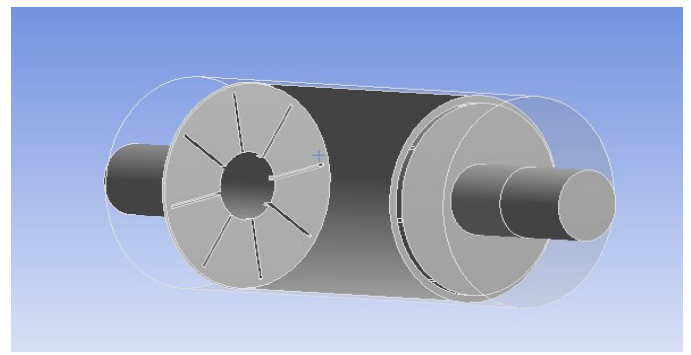

Fig. 6. Case-1 model

G. Case-2 12 Slot Model

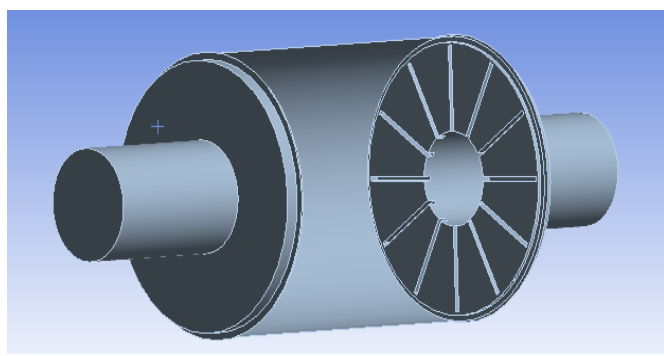

Fig. 7. 12 Slot Model

H. Case-3 16 Slot Model

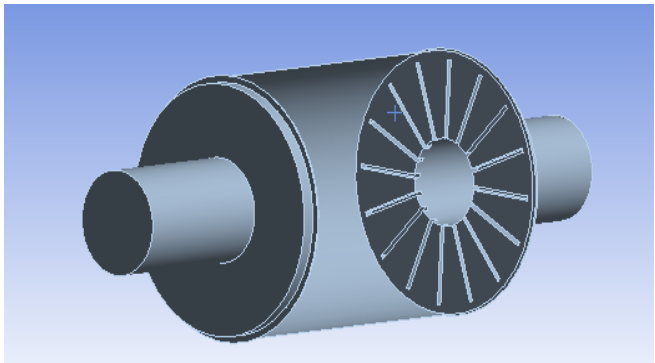

Fig. 8. 16 Slot Model

I. Meshing

Case-1 


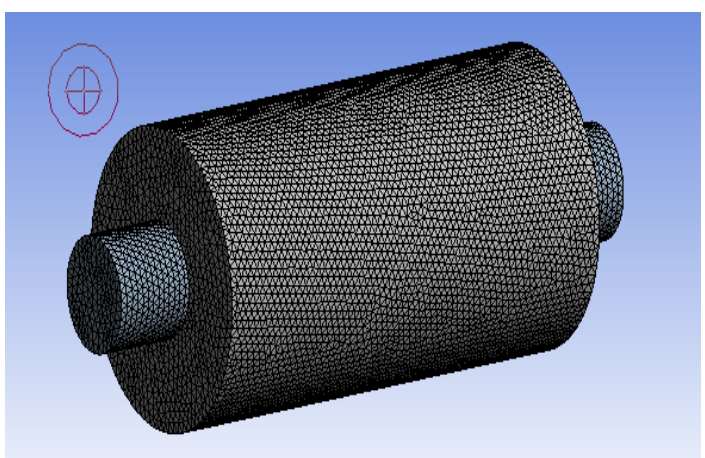

Fig. 9. Meshing Total No. of Nodes: 39855 \& Total No. elements: 148187

Case-2.

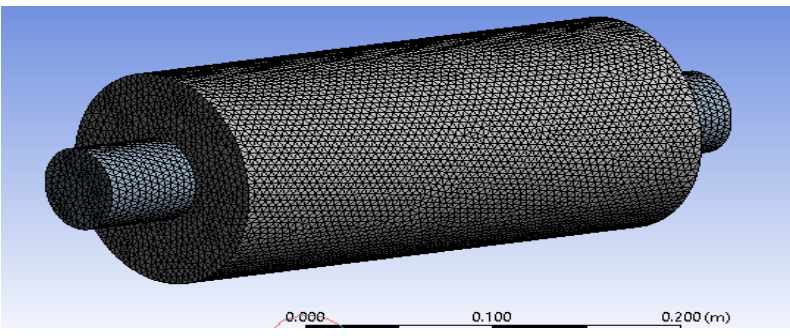

Fig. 10. Meshing Total No. of Nodes: 39349\& Total No. elements: 145964

Case-3

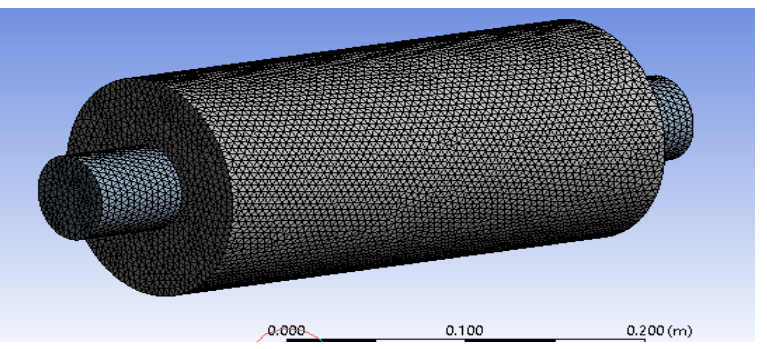

Fig. 11. Meshing Total No. of Nodes: $39324 \&$ Total No. elements: 145964

\section{J. Defining Material Properties}

$>$ Air properties

\begin{tabular}{|c|c|}
\hline Properties & Values \\
\hline Density $\left(\mathrm{kg} / \mathrm{m}^{\wedge} 3\right)$ & 1.225 \\
\hline Specific heat $(\mathrm{j} / \mathrm{kg}-\mathrm{k})$ & 1006.43 \\
\hline Thermal conductivity $(\mathrm{w} / \mathrm{m}-\mathrm{k})$ & 0.0242 \\
\hline
\end{tabular}

Table 1:- Air Properties

\section{K. Boundary Condition}

Define inlet and outlet for CFD analysis. The rotor is modelled as a solid where the rotor is rotating at 1500 rpm. No slip boundary condition is used for the rotor surfaces with a constant temperature of $150^{\circ} \mathrm{C}$. However, the surfaces of the shaft outside the air domain were kept at ambient temperature $40^{\circ} \mathrm{C}$. On the other hand, the stator internal surface was modelled as a stationary wall where a virtual wall thickness of $50 \mathrm{~mm}$ was considered. A convective heat transfer coefficient of $10 \mathrm{~W} / \mathrm{m} 2 \mathrm{~K}$ was imposed at the external surface of the virtual thick wall together with a free stream temperature of $40^{\circ} \mathrm{C}$, which is the ambient temperature.

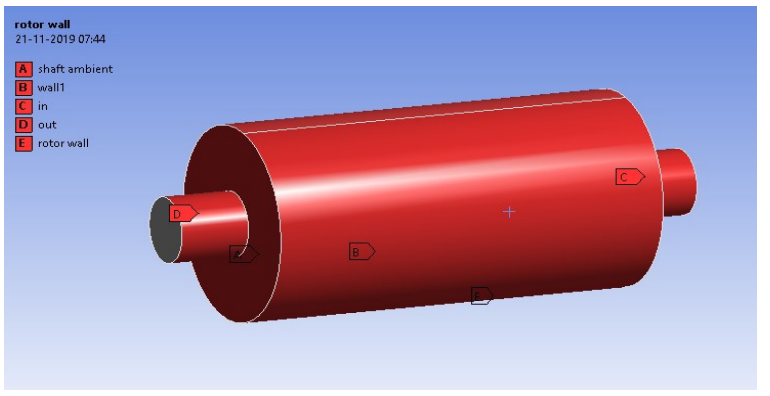

Fig. 12. Define boundary conditions

\begin{tabular}{|c|c|}
\hline Boundary conditions & Values \\
\hline Inlet velocity & Velocity Outlet \\
\hline Outlet & Pressure outlet \\
\hline Rotation velocity & 1500 RPM \\
\hline
\end{tabular}

L. Case-1 Result

i. Velocity contours

The maximum velocity $9.688 \mathrm{~m} / \mathrm{s}$ in first case. The blue color shows minimum velocity area. And the yellow color show maximum velocity area.

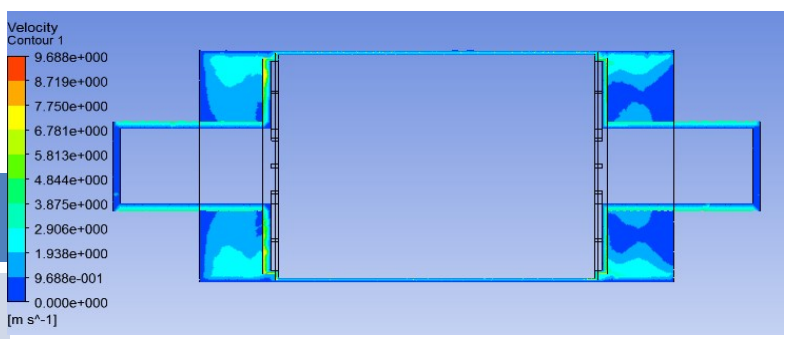

Fig. 13. Velocity contours

\section{ii. Temperature contours}

Maximum temperature inside the rotor casing was 390K and minimum temperature 300k.the light blue color show 
the minimum temperature region and red color show maximum temperature region.

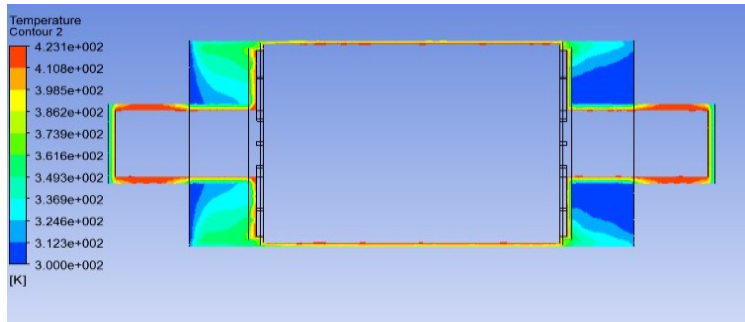

Fig. 14. Temperature contours

\section{iii. Velocity stream line}

Velocity streamline shows the flow of air inside the rotor casing

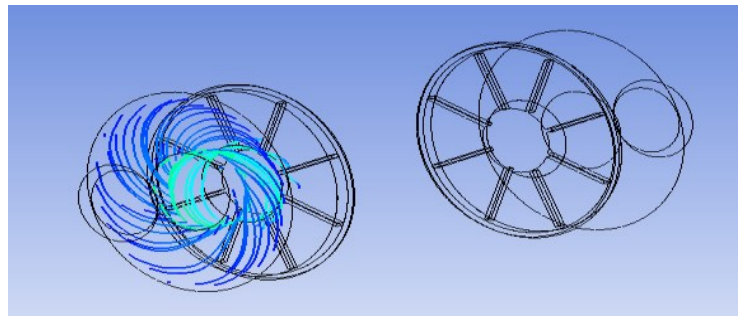

Fig. 15. Velocity stream line.

\section{iv. Pressure contours}

Pressure inside the rotor casing was 2.177Pa.the light blue color show the minimum pressure region and red color show maximum pressure region

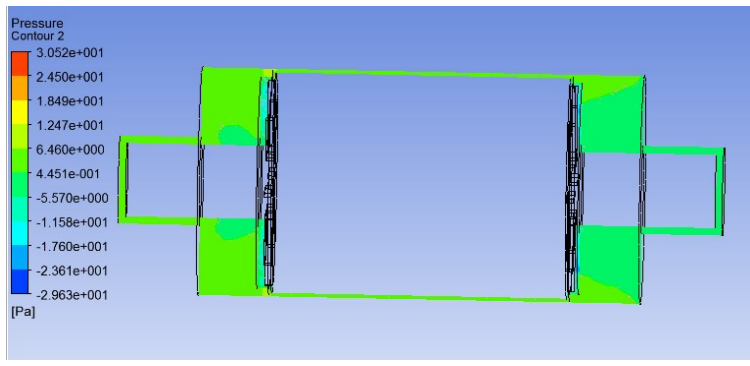

Fig. 16. Pressure contours

M. Case-2 Result

i. Temperature contours

Maximum temperature inside the rotor casing was $373 \mathrm{~K}$ and minimum temperature $300 \mathrm{k}$.the light blue color show the minimum temperature region and red color show maximum temperature region.

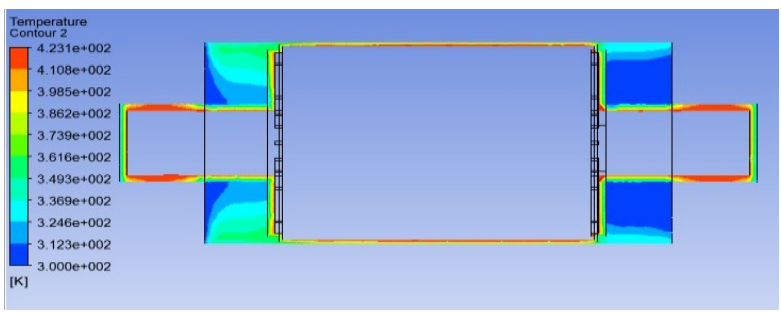

Fig. 17. Temperature contours

\section{ii. $\quad$ Velocity contours}

Maximum velocity inside the rotor casing was $9.073 \mathrm{~m} / \mathrm{s}$. The light blue color show the minimum velocity region and red color show maximum velocity region.

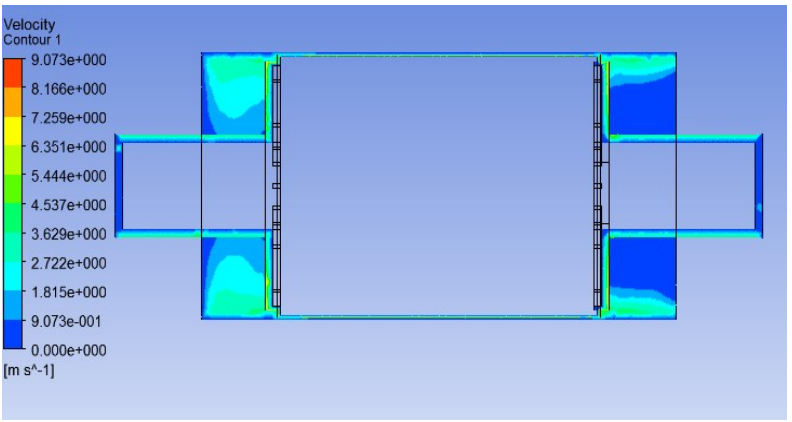

Fig. 18. Velocity contours

\section{iii. Streamline}

Velocity streamline shows the flow of air inside the rotor casing

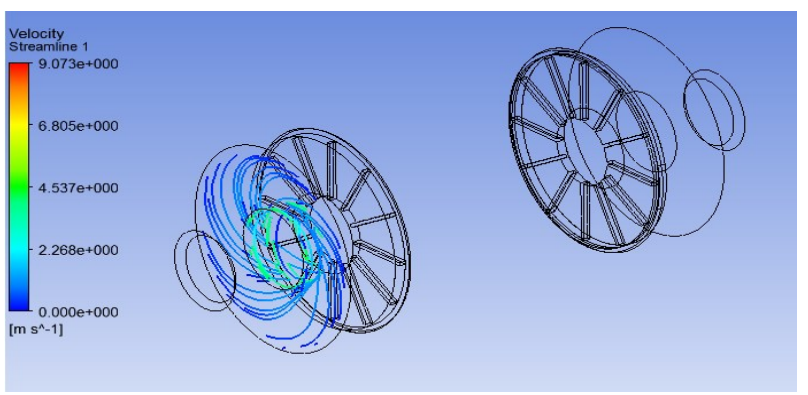

Fig. 19. Velocity stream line

\section{iv. Pressure contours}

Pressure inside the rotor casing was 2.077Pa.the light blue color show the minimum pressure region and red color show maximum pressure region 


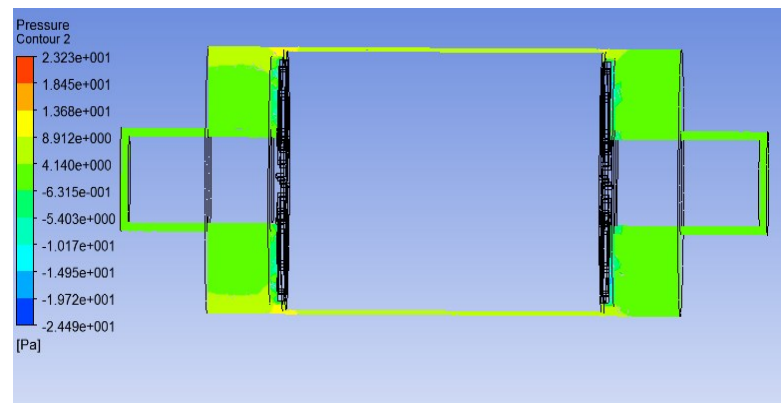

Fig. 20. Pressure contours

\section{N. Case-3 Result}

i. Temperature contours

Maximum temperature inside the rotor casing was $349 \mathrm{~K}$ and minimum temperature $300 \mathrm{k}$.the light blue color show the minimum temperature region and red color show maximum temperature region.

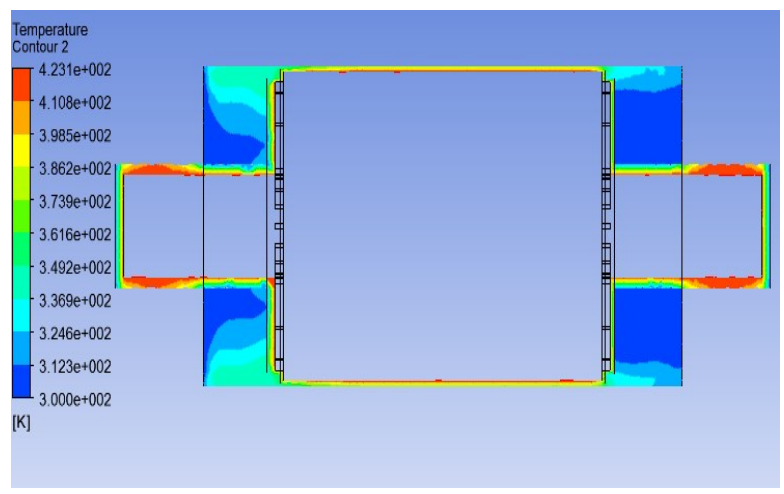

Fig. 21. Temperature contours

\section{ii. Velocity contours}

Maximum velocity inside the rotor casing was $9.087 \mathrm{~m} / \mathrm{s}$. The light blue color show the minimum velocity region and red color show maximum velocity region.

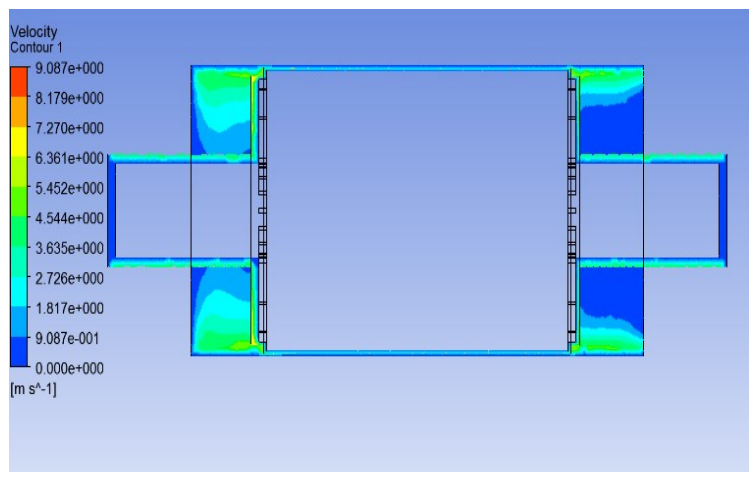

Fig. 22. Velocity contours

\section{iii. Streamline}

Velocity streamline shows the flow of air inside the rotor casing

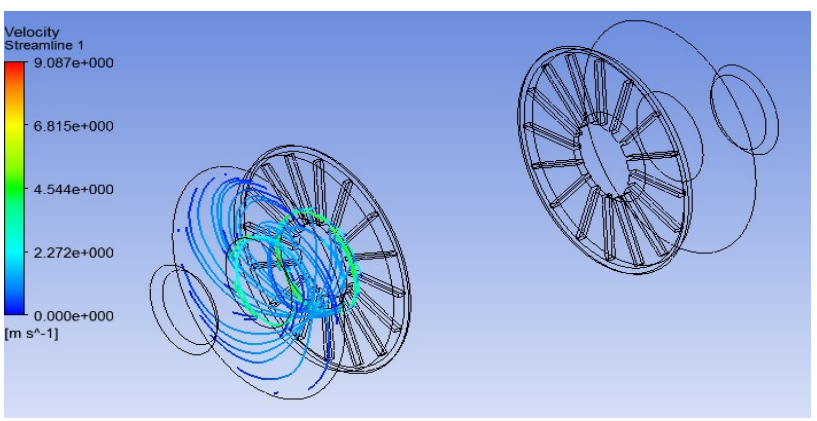

Fig. 23. Velocity stream line

\section{iv. Pressure contours}

Pressure inside the rotor casing was 1.26Pa.the light blue color show the minimum pressure region and red color show maximum pressure region

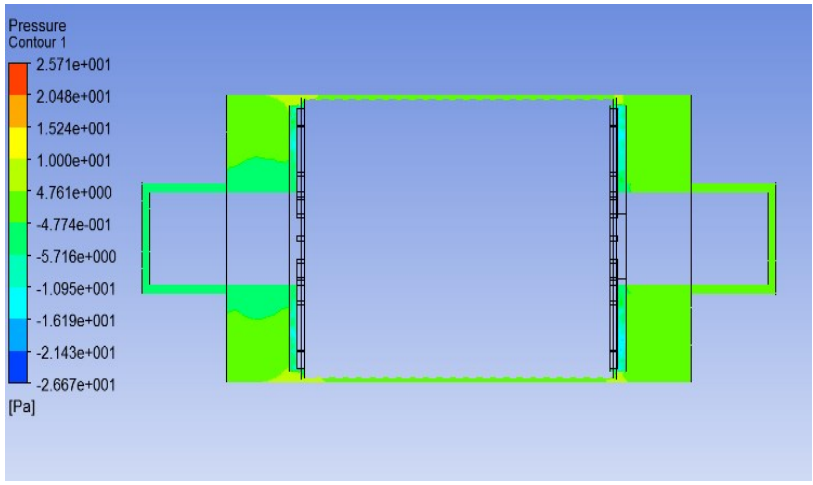

Fig. 24. Pressure contours

\section{v. Turbulence kinetic energy}

In fluid dynamics, turbulence kinetic energy (TKE) is the mean kinetic energy per unit mass associated with eddies in turbulent flow. Physically, the turbulence kinetic energy is characterized by measured root-mean-square (RMS) velocity fluctuations. In Reynolds-averaged Navies Stokes equations, the turbulence kinetic energy can be calculated based on the closure method, i.e. a turbulence model.

\section{a. Case-1}

TKE inside the rotor casing was $2.621 \mathrm{~J} / \mathrm{kg}$. the light blue color show the minimum TKE region and red color show maximum TKE region 


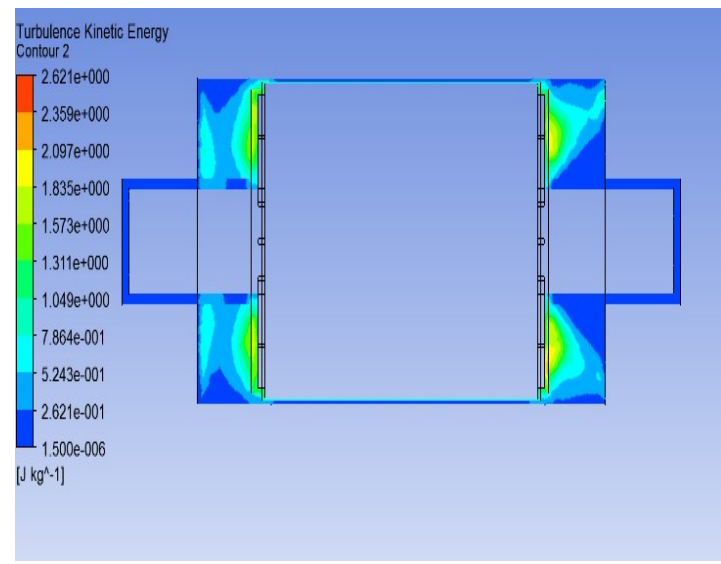

Fig. 25. Turbulence kinetic energy contours

\section{b. Case-2}

TKE inside the rotor casing was $2.8 \mathrm{~J} / \mathrm{kg}$. The light blue color show the minimum TKE region and red color show maximum TKE region

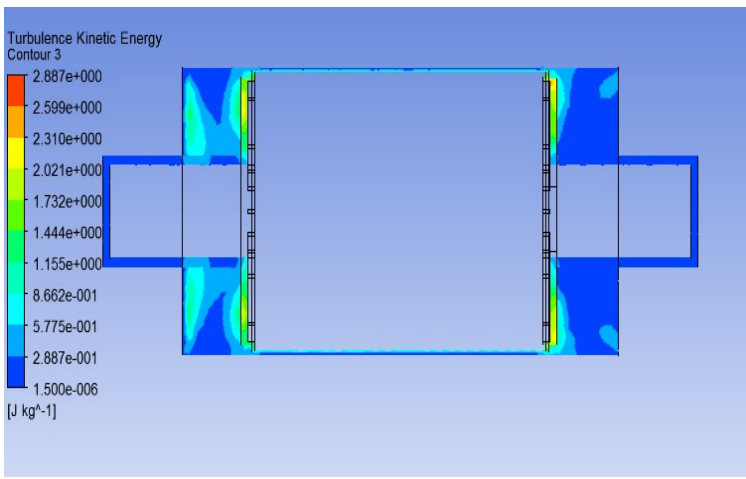

Fig. 26. Turbulence kinetic energy contours

\section{c. Case-3}

TKE inside the rotor casing was $3.44 \mathrm{~J} / \mathrm{kg}$. The light blue color show the minimum TKE region and red color show maximum TKE region

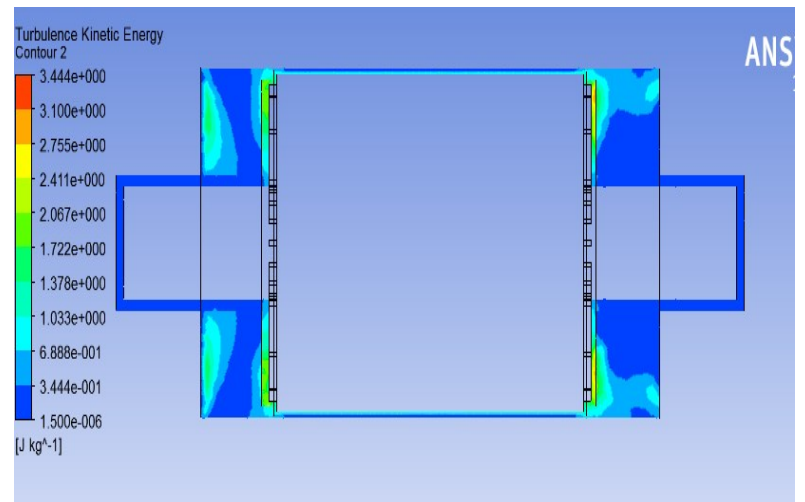

Fig. 27. Turbulence kinetic energy contours

\section{RESULTS}

A. CFD Analysis of Rotor Machine.

The velocity 9.99 and temperature $390 \mathrm{k}$ in base paper, due to increasing turbulence effect the velocity inside the rotor decreases and temperature inside the rotor also decrease with velocity. And cooling effect inside the rotor increases.

Table 2 Results of CFD analysis of rotor machine.

\begin{tabular}{|c|c|c|}
\hline CASE & Temperature & Velocity \\
\hline Base paper Result & $390 \mathrm{k}$ & 9.99 \\
\hline CASE-1 & $390 \mathrm{k}$ & 9.688 \\
\hline CASE-2 & $373 \mathrm{k}$ & 9.07 \\
\hline CASE-3 & $349 \mathrm{k}$ & 9.087 \\
\hline
\end{tabular}

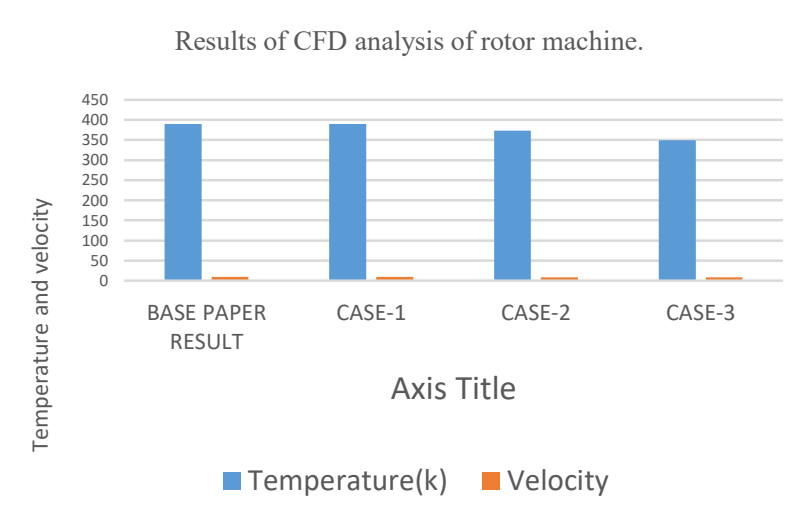

Fig. 28. Results of CFD analysis of rotor machine.

\section{B. Temperature inside the Rotor Machine}

The temperature fig. 29 show the comparative result of base paper result and case 1, 2, 3 .

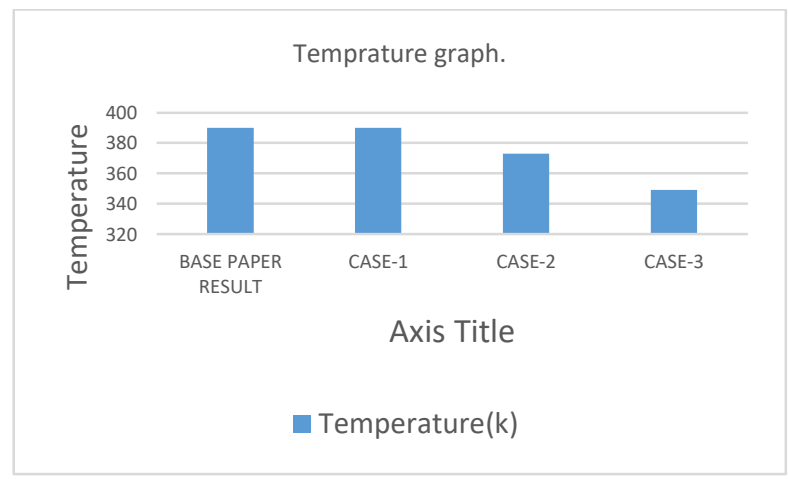

Fig. 29. Temperature inside the rotor machine

C. Velocity inside the Rotor Machine 
The fig. 30 show the comparative result of base paper result and case 1, 2, 3 .

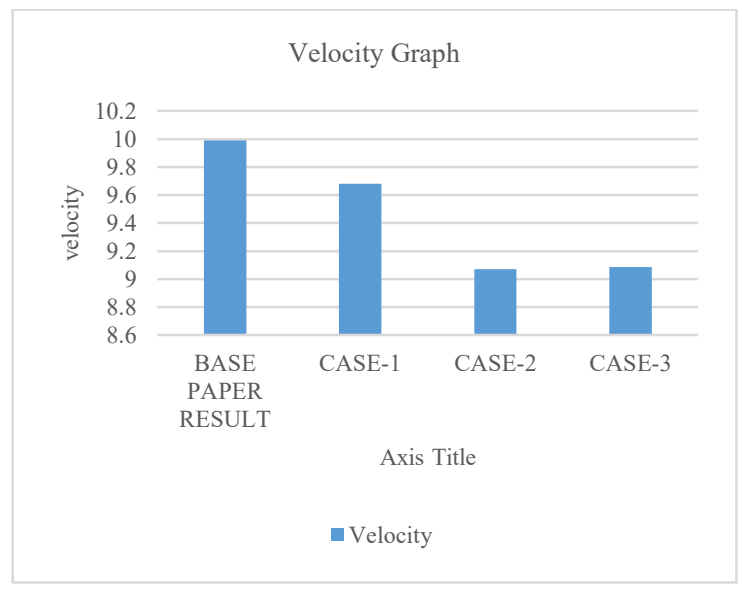

Fig. 30. Velocity inside the rotor machine

\section{Pressure inside the Rotor Machine}

When the pressure increases then the temperature also increases. When the pressure decreases, then the temperature decreases.

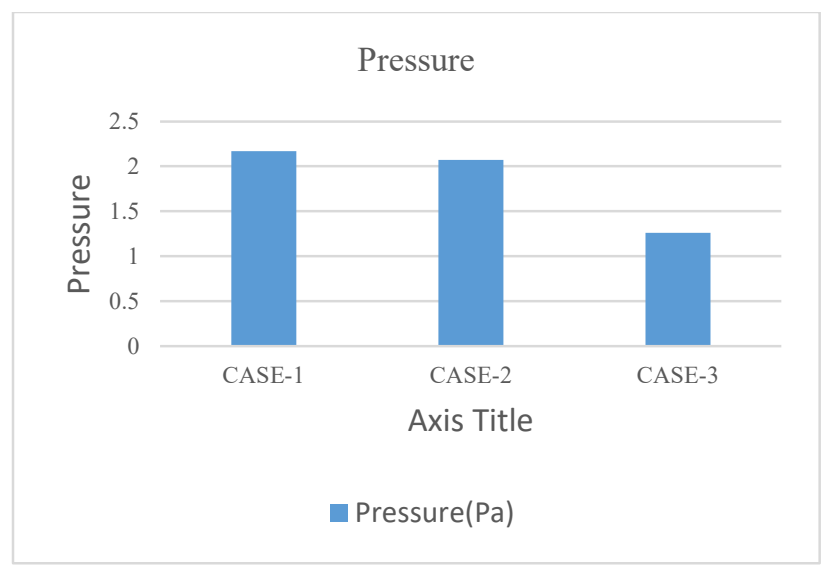

Fig. 31. Pressure inside the rotor machine

Table 3. comparison

\begin{tabular}{|c|c|c|c|c|}
\hline & velocity & temperature & $\begin{array}{c}\text { Nusselt } \\
\text { number }\end{array}$ & $\begin{array}{c}\text { heat } \\
\text { expiation }\end{array}$ \\
\hline $\begin{array}{c}\text { Case- } \\
1\end{array}$ & $2.4 \times 10^{-5}$ & $4.2 \times 10^{5}$ & 9.036 & 28.59 \\
\hline $\begin{array}{c}\text { Case- } \\
2\end{array}$ & $2.308 \times 10^{5}$ & $4.5 \times 10^{5}$ & 9.188 & 28.43 \\
\hline $\begin{array}{c}\text { Case- } \\
3\end{array}$ & $2.046 \times 10^{5}$ & $5.7 \times 10^{5}$ & 9.726 & 27.66 \\
\hline
\end{tabular}

E. Taylor number graph
The fig. 32 show the comparative result of base paper result and case $1,2,3$.

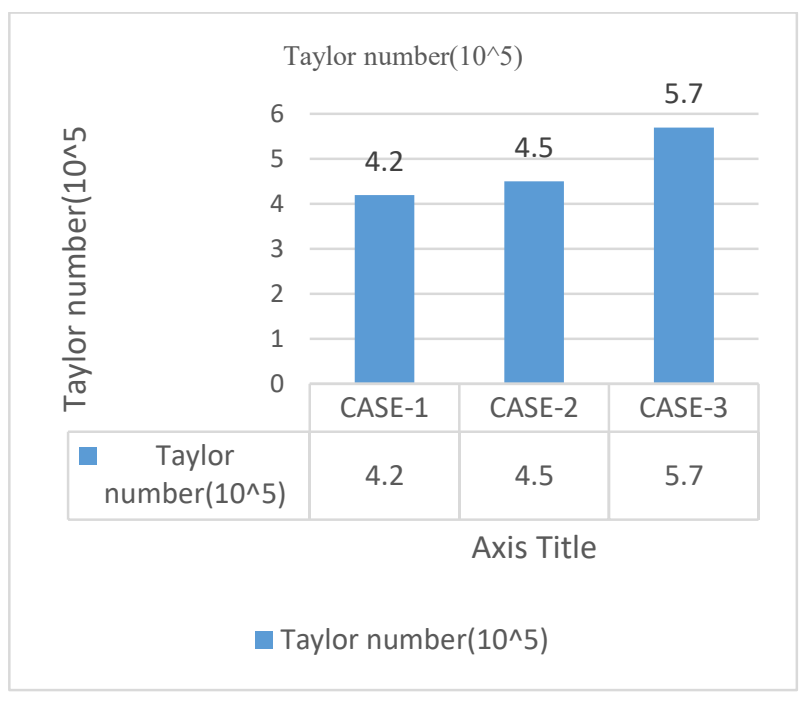

Fig. 32. Taylor number graph

\section{F. Nusselt number graph}

The fig. 33 show the comparative result of base paper result and case $1,2,3$.

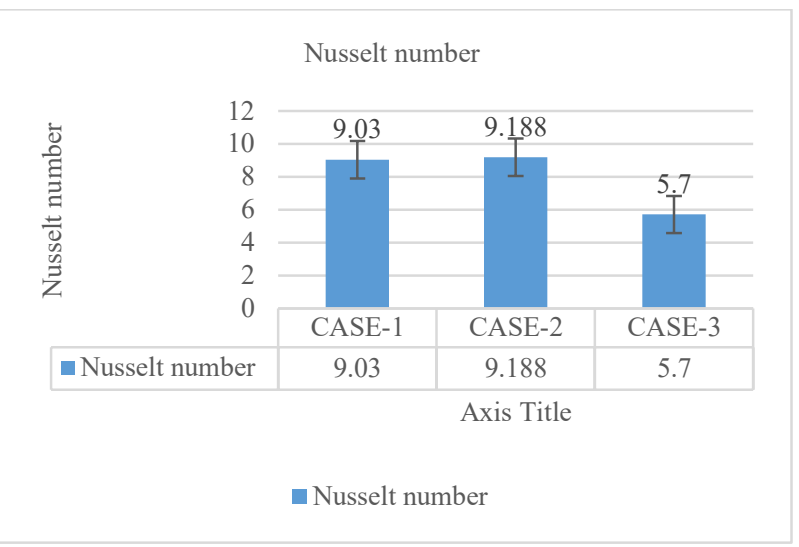

Fig. 33. Nusselt number graph

\section{Conclusion}

1. The model presented in this study captures the complex Taylor vortex flow very well while providing detailed insight of the flow and heat transfer inside the air-gap.

2. The model predicts the heat transfer coefficient with overall good accuracy. The simulation results pinpoint also the periodic heat transfer pattern from the rotor surface and this provides useful information for the prediction of the temperature distribution inside the rotating electrical machine. 
3. The simulation results of case- 1 show about $117^{\circ} \mathrm{C}$ temperature inside the rotor machine. Then increase the number of slot inside the rotor machine the total temperature of the rotor machine decreases up to $76^{\circ} \mathrm{C}$. Due to low temperature total efficiency of the system increases. And also reduces the loss due to heat.

4. The turbulence effect inside the rotor increase in third case. Due to turbulence effect the air cover large amount of area inside the rotor.so total temperature of the rotor casing decreases. Pressure and Temperature Relationship.

5. In a system where volume is held constant, there is a direct relationship between Pressure and Temperature. For this case, when the pressure increases then the temperature also increases. When the pressure decreases, then the temperature decreases. So pressure in third case decrease upto1.26 $\mathrm{Pa}$ and temperature $76^{\circ} \mathrm{C}$.

\section{FUTURE SCOPE}

For future study the turbulence effect also improved by using optimization method. The overall design of the rotor optimized by ANSYS design optimization method. The optimization method is very effective and suitable method to improve any design.

\section{REFERENCES}

[1] Berker Bilgin, Jianbin Liang "Modeling and Analysis of Electric Motors: State-of-the-Art Review" July 2019.

[2] K. Wang, J. Li "Flux-Focusing Permanent Magnet Machines with Modular Consequent-Pole Rotor" DOI: 10.1109/TIE.2019 .2922922 June 2019.

[3] Sara Sadr, Abdelli Abdenour "Comprehension and Estimation of Windage Losses in Rotor Slotted Air Gaps of Electrical Machines using CFD-LES methods" DOI: 10.1109/ECCE.2019.8912698 October 2019.

[4] Jungmayr, G., Marth, E., \& Segon, G. (2019). Magnetic-Geared Motor in Side-by-Side Arrangement - Concept and Design. 2019 IEEE International Electric Machines \& Drives Conference (IEMDC). doi:10.1109/iemdc.2019.8785275

[5] Salvatore La Rocca "Thermal modelling of a totally enclosed fancooled electrical machine" July 2019

[6] Mehmet C Kulan, Nick J Baker "Development of a Thermal Equivalent Circuit to Quantify the Effect of Thermal Paste on Heat Flow through a Permanent Magnet Alternator" October 2018.

[7] Xu Liu, Gang Liu "A Loss Separation Method of a High-Speed Magnetic Levitated PMSM Based on Drag System Experiment Without Torque Meter" DOI: 10.1109/TIE.2018.2844795 June 2018.

[8] K. Rönnberg, M. E. Beniakar "Thermal Modelling of Totally Enclosed Fan Cooled motors" 2018.

[9] Kevin Anderson, Jun Lin "Experimental and Numerical Study of Windage Losses in the Narrow Gap Region of a High-Speed Electric Motor" DOI: 10.3390/fluids3010022 March 2018.
[10] Md Lokman Hosain, Rebei Bel Fdhila "Air-Gap Flow and Thermal Analysis of Rotating Machines Using CFD" Energy Procedia 105 ( 2017 ) $5153-5159$ 